\title{
A Specific Study on the Impacts of PM2.5 on Urban Heat Islands with Detailed In Situ Data and Satellite Images
}

\author{
Cheng Zhong ${ }^{1}$, Chen Chen ${ }^{2}$, Yue Liu ${ }^{1}$, Peng Gao ${ }^{3}$ and Hui Li ${ }^{2, *}$ \\ 1 Three Gorges Research Center for Geo-Hazard, Ministry of Education, China University of Geosciences, \\ Wuhan 430074, China; zhonglxm@cug.edu.cn (C.Z.); yliutgrc@sohu.com (Y.L.) \\ 2 School of Earth Science, China University of Geosciences, Wuhan 430074, China; chenchen@cug.edu.cn \\ 3 Department of Geography, University of South Carolina, 709 Bull St., Columbia, SC 29208, USA; \\ gaop@mailboix.sc.edu \\ * Correspondence: rslihui@cug.edu.cn
}

Received: 29 October 2019; Accepted: 1 December 2019; Published: 10 December 2019

check for updates

\begin{abstract}
Rapid urbanization often results in serious urban heat islands (UHI) and fine particulate matter (PM2.5) concentration. Previous studies found it was hard to evaluate the haze contribution to the UHI quantitatively, because of the complex properties of the atmosphere aloft and the irregular alteration of PM2.5 loads. Taking Beijing as the study site, where detailed in situ PM2.5 concentration data, canopy thermal data and MODIS land surface temperature (LST) products were all available in 2015, this study investigated the impacts of PM2.5 on both surface UHI intensity (SUHII) and canopy UHI intensity (CUHII) at daytime and night. The results reveal that the CUHII are almost unchanged throughout the year, while SUHII varies greatly in both temporal axis and spatial distribution. PM2.5 concentration has significant negative impacts on mean SUHII $(r=-0.6115)$ and daytime SUHII $(r=-0.6164)$, and less significant negative impact on CUHII $(r=-0.51999)$. However, the contribution of PM2.5 concentration to nighttime SUHI is not significant. This specific study checked and improved previous works on this topic, with detailed in situ data and satellite images. The results of this work can enhance our understanding of the dynamics and driving mechanism of urban thermal environment.
\end{abstract}

Keywords: urban heat island; atmospheric fine particles; land surface temperature; great metropolis

\section{Introduction}

Currently, about $54 \%$ of the world's population lives in urban areas. This number is projected to reach $67.2 \%$ in 2050 [1]. Urban expansion inevitably converts the natural and semi-natural ecosystems into impervious surfaces and thus becomes the most widespread anthropogenic cause of thermal environment change [2,3]. In addition, population growth in urban areas has led to an increase in anthropogenic heat emissions from vehicle transportation, civil and industrial activities $[4,5]$. Consequently, the air or surface temperature in urban areas tends to be higher than the surrounding suburban, which is called Urban Heat Island (UHI). The mechanism underlying the pronounced surface climate changes is generally thought to be the large differences in the surface roughnesses, convection efficiency, artificial heating and building densities between rural and urban land [6,7]. High temperatures in urban areas not only accelerate the formation of urban smog and polluted air, but also greatly increase energy consumption in summer, contributing to global warming [8-10]. Many studies believe that UHIs are mainly affected by land use/land cover and its component and configuration, and socioeconomic factors (e.g., GDP, population, and so on) [11-13]. 
Fine particulate matter (PM2.5), which is equal to or less than $2.5 \mu \mathrm{m}$ in aerodynamic diameter, can carry heavy metals and sulfates [14]. The high concentration of PM2.5 leads to lower atmospheric visibility and respiratory diseases, even cancer [15]. PM2.5 mainly originates from the products of our daily activities, such as vehicle exhaust, marine aerosols, coal and fuel oil combustion, burning of agricultural wastes, paved road dust, and secondary sulfates, etc. [16]. Owing to population expansion and rapid urbanization, many Chinese cities have suffered from high concentration of the fine particulate matter for a long time [17-19]. This problem is especially drawing global attention, as it causes many environmental and ecological problems [20-23].

Several studies have taken into account the impacts of fine particles on UHIs. For example, in an aerosol-climate study, a correlation between the aerosol optical depths and changes in regional temperatures over Europe was found with the regional chemistry climate model COSMO-ART [24]. Reference [25] found that different PM2.5 levels in summer caused a little change of temperature, and the chemical speciation determined whether the particles only scattered light or also absorbed light. Due to the scattering characteristics of the particles, it can cool the urban temperature strongly. Thus, the increase of the particle concentrations often causes the decrease of urban temperature [26,27]. Reference [28] provided evidence for a long-held hypothesis that the biogeochemical effect of urban aerosol or haze pollution was also a contributor to the UHI, based on satellite observations and urban climate model calculations. Reference [12] studied the impact of PM2.5 on the urban heat island (UHI) and reported that UHI intensity could be weakened during the day, affected by fine particles. Later, Reference [29] found that higher PM2.5 concentrations led to lower UHI intensity, especially during the daytime, and the UHI can be reduced by up to $1 \mathrm{~K}$. However, Reference [30] stated the haze contribution to the daytime UHI was uncertain, while nighttime UHI could be intensified by the haze, based on data from 39 cities in China. Numerical models used to quantify the effects of fine particles revealed that their radiative forcing is different in urban and suburban regions, and different at daytime and night, because different time or regions had different PM2.5 loads, which caused different surface temperature cooling effects [31].

Beijing city has suffered from serious UHI and high PM2.5 concentration for a long time, which are caused by rapid urbanization and economic development. For monitoring the air quality and temperature, tens of new meteorological stations and air quality stations have been built since 2012. Then, the city has most monitoring stations all over China, and can provide detailed data for related studies. Based on the meteorological data and air quality data of this city, this study aims to: (1) check and improve the previous works on the relationship between PM2.5 concentration and UHI; (2) investigate the variation of the city's thermal environment and air quality, and the impacts of fine particles on UHI. The results of this work are expected to deepen our understanding of the dynamics and driving mechanism of a metropolis's thermal environment, and support managers and planners to optimize the strategies for alleviating these problems.

\section{The Study Site and Data}

\subsection{Study Site}

Beijing City, the political and cultural center of China, is located at $39^{\circ} 26^{\prime}-41^{\circ} 03^{\prime} \mathrm{N}$ and $115^{\circ} 25^{\prime}-117^{\circ} 30^{\prime}$ E (Figure 1), and occupies a land area of 16,800 square kilometers. The city has a temperate monsoon climate, with mild winters (annual minimum temperature is $-2.37^{\circ} \mathrm{C}$ ) and moderately hot summers (annual maximum temperature is $25.4^{\circ} \mathrm{C}$ ). The northern and western part of the city is mountainous (near the Taihang Mountains and the Yanshan mountains), with an elevation of $200-1000 \mathrm{~m}$. The central and southern part is located in the North China plain and has been well developed.

As one of the largest cities in China, Beijing is undergoing the most dramatic expansion in its history. On one hand, the rapid expansion brings great benefits to citizens, such as job opportunities, convenient transportation, beautiful views, and modern residence environments. On the other hand, it 
induces serious air pollution (i.e., PM2.5), UHI and water pollution to the city. Since 1998, an intensified air pollution control program, including energy infrastructure optimization, coal-fired pollution control and vehicle emission controls has been applied to reduce air pollution. By 2015, PM2.5 fell by $35 \%$ in the downtown of Beijing, and by $25 \%$ in suburb regions. As the capital, the city has tens of meteorological stations and air quality stations, much more than most other cities. Thus, the city is the best site to investigate the impacts of PM2.5 on urban heat island in China.

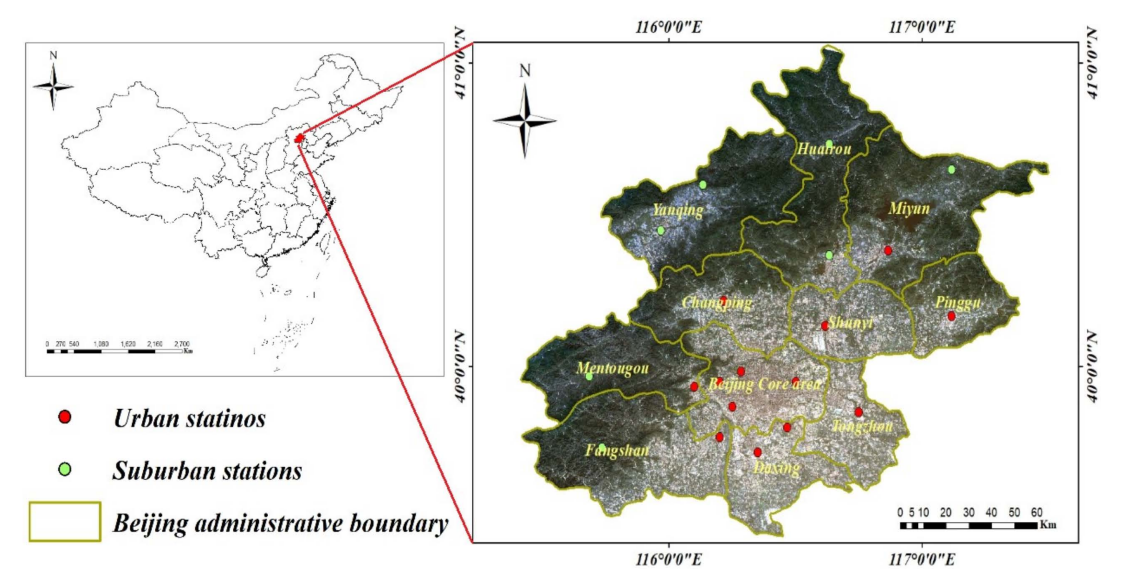

Figure 1. The study area and meteorological monitoring stations.

\subsection{Data Set}

\subsubsection{PM2.5 Concentration}

Since 2012, many air quality stations have been built or updated to monitor PM2.5 concentration within the city. However, not all stations can provide stable and continuous data. It was found that the number of available stations and records in 2015 is greater than those in other years. Thus, this study focused on the year 2015, when the PM2.5 concentration, canopy thermal data and MODIS LST products were all available.

Daily PM2.5 concentration of 13 air quality stations within the city in 2015 was collected from the China National Environmental Monitoring Center (http://www.cnemc.cn/). Considering the number of stations is limited, the spatial distribution of PM2.5 was not investigated in this study. The mean PM2.5 concentration of the city was generated by simply averaging the data from all stations.

\subsubsection{Canopy Thermal Data}

The canopy thermal data was collected from 20 meteorological stations within the city. Daily data of these stations in 2015 was collected from the China National Meteorological Information Center (http://data.cma.cn/). The 20 meteorological stations were further classified into 13 urban stations and 7 suburban stations (as shown in Figure 1), according to their locations in the land cover map, which was downloaded from the Resource and Environment Data Cloud platform of the Chinese Academy of Sciences (http://www.resdc.cn/lds.aspx).

\subsubsection{Surface Thermal Data}

The surface thermal data was retrieved from the 5-day, $1 \mathrm{~km}$ MODIS land surface temperature (LST) products. MODIS LST products were downloaded from the official website of Geospatial Data Cloud (http://www.gscloud.cn/). After images seriously contaminated by clouds and fogs were removed, 47 pairs of images (having both the daytime and nighttime images on the same day) were available from the original 146 images. Then, the Kriging interpolation was carried out to repair pixels lost to LST values in these images, which might be caused by clouds and fog. Lastly, the mean LST products of these days were generated by averaging corresponding daytime and nighttime images. 


\section{Methods}

\subsection{Canopy Urban Heat Island Intensity}

Urban canopy refers to the urban atmosphere between the ground level and the average building height. Canopy Urban heat islands (CUHII) indicates urban atmospheric heat islands, and CUHII is usually measured by meteorological stations. The difference between the urban canopy temperature and suburban canopy temperature is considered as CUHII. Here, the data from thirteen urban meteorological stations and seven suburban meteorological stations are used to calculate the two temperatures respectively. The method is simply shown as follows:

$$
\text { CUHII }=C T_{\text {urban }}-C T_{\text {suburban }}=\frac{1}{13} \sum_{i=1}^{13} C T_{i}-\frac{1}{7} \sum_{j=1}^{7} C T_{j}
$$

where the $C T_{\text {urban }}$ and $C T_{\text {suburban }}$ represent the mean urban temperatures and mean suburban temperatures respectively; $C T_{i}$ and $C T_{j}$ indicate the temperature from an urban station and that from a suburban station respectively; CUHII represents the Canopy Urban Heat Island Intensity.

\subsection{Surface Urban Heat Island Intensity}

Surface Urban Heat Island (SUHI) represents the urban surfaces heat islands, and SUHI intensity is measured by surface stations or satellites. In the MODIS LST image, all pixels within the city are used to calculate the SUHII. Generally, the temperature difference between the urban area and adjacent suburban area is used to define the SUHII intensity (SUHII),

$$
\text { SUHII }=T_{\text {urban }}-T_{\text {suburbs }}
$$

Here, $T_{\text {urban }}$ represents the mean temperature of the urban area, and $T_{\text {suburbs }}$ indicates the mean temperature of the suburb area. The urban area was defined by combining the built-up area in MODIS land cover data and the regions where nighttime value is bigger than 10 in DMSP/OLS data, while the left area was considered as the suburb area. This SUHII is the mean intensity of the study area, and could be used to analyze the general tendency of Beijing's thermal environment.

In order to depict the SUHII at each pixel, the difference between its temperature value $\left(S T_{i}\right)$ and the average value $\left(S T_{\text {mean }}\right)$ is considered as detailed SUHII:

$$
\text { SUHII }=S T_{i}-S T_{\text {mean }}=S T_{i}-\frac{1}{n} \sum S T_{i}
$$

In Equation (3), $T_{i}$ indicates the temperature value of a pixel, and $n$ represents the total number of pixels within BTH; $T_{\text {mean }}$ is the mean surface temperature of BTH. If the temperature value at a pixel $\left(T_{i}\right)$ is bigger than the average value $\left(T_{\text {mean }}\right)$, the pixel is considered as a SUHII pixel. Then, the spatial distribution of heat islands could be mapped. With Equation (3), the daytime SUHII and nighttime SUHII maps can also be generated from MODIS daytime and nighttime LST images respectively.

\subsection{Pearson Correlation Coefficient}

In this study, the Pearson correlation coefficient was used to investigate the impacts of PM2.5 concentration on CUHII and SUHII. The Pearson correlation coefficient, also referred to as Pearson's $r$, is a measure of the linear correlation between two variables $X$ and Y. According to the Cauchy-Schwarz inequality, it has a value between +1 and -1 , where 1 is total positive linear correlation, 0 is no linear correlation, and -1 is total negative linear correlation. The formula for the Pearson correlation is shown as below:

$$
r_{x y}=\frac{\sum_{i=1}^{n}\left(x_{i}-\bar{x}\right)\left(y_{i}-\bar{y}\right)}{\sqrt{\sum_{i=1}^{n}\left(x_{i}-\bar{x}\right)^{2}} \sqrt{\sum_{i=1}^{n}\left(y_{i}-\bar{y}\right)^{2}}}
$$


where $x_{i}$ and $y_{i}$ represent the variables on day $i ; \bar{x}$ and $\bar{y}$ indicate the mean value of each variable, respectively. The $r_{x y}$ represents the correlation coefficient between $x$ and $y$.

\section{Results}

\subsection{Temporal Dynamics of PM2.5, CUHII and SUHII}

In order to analyze the temporal dynamics of CUHII, SUHII and PM2.5, their monthly mean values in 2015 were calculated and shown in Figure 2.

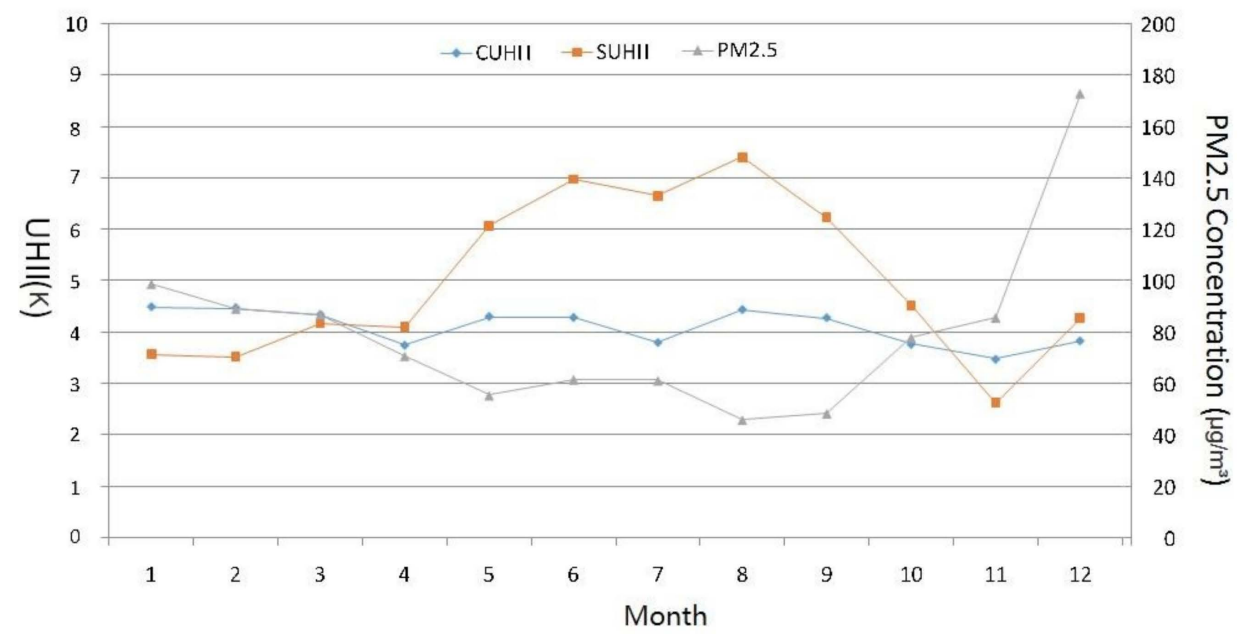

Figure 2. The monthly mean value of CUHII, SUHII and PM2.5 in 2015.

The monthly values of CUHII did not change a lot throughout the year. The monthly values of SUHII became much larger from April to October. That was mainly because man-made materials are the dominant surface in urban areas, which will emit a relatively greater proportion of incident solar energy sooner; while natural surfaces (water, vegetation and so on) are the dominant in suburban areas, which could keep most of the energy for a longer time. In summer, the difference between the two emissions becomes larger, as the solar radiation is very strong at that time; while the difference can be ignored in winter. The monthly mean PM2.5 concentration of the city ranged from 40 to $180 \mu \mathrm{g} / \mathrm{m}^{3}$. The most serious air pollution happened in December, because of the civil heating and stable air; in summer, the PM2.5 concentration decreased a lot, which is mainly influenced by the monsoon.

\subsection{The Spatial Distribution of SUHII under Different PM2.5 Levels}

As the number of meteorological stations is limited, it is meaningless to map the spatial distribution of CUHII. Fortunately, the spatial distribution of SUHII could be mapped from MODIS LST products, with Equation (2). Then, the impact of PM2.5 on the spatial distribution of SUHII was investigated in this study. In order to visualize the impact simply, the PM2.5 concentration was first categorized into three levels, based on the variation range of PM2.5 in this city: (1) light (PM2.5 $<50 \mathrm{ug} / \mathrm{m}^{3}$ ); (2) moderate $\left(50 \mathrm{ug} / \mathrm{m}^{3}<\mathrm{PM} 2.5<100 \mathrm{ug} / \mathrm{m}^{3}\right)$; and (3) serious (PM2.5 $\left.>100 \mathrm{ug} / \mathrm{m}^{3}\right)$. Then, the mean SUHII value of each pixel under a certain PM2.5 level was calculated and mapped (Figure 3).

In all panels, regions having positive SUHII mainly distributed in the developed area (the central, eastern and southern parts of the city), while regions having negative SUHII mainly distributed in the mountainous area (the northern and western parts). It is noticed that the central part (the most developed region of the city) always had the highest SUHII. These indicate that the spatial distribution of SUHII mainly depends on the type of land surface, which has been proven by many related researches.

In the figure, the distribution of SUHII was also significantly influenced by the PM2.5 concentration level. For example, the region where SUHII $>4$ became much less in Figure $3 b$ than that in Figure $3 a$, 
and almost disappears in Figure 3c. Additionally. all regions having a higher value (SUHII $>1$ ) followed the similar variation pattern. This means the area of heat island decreased dramatically when the PM2.5 concentration level lifted. The results imply that the PM2.5 concentration had a significant negative impact on SUHII.

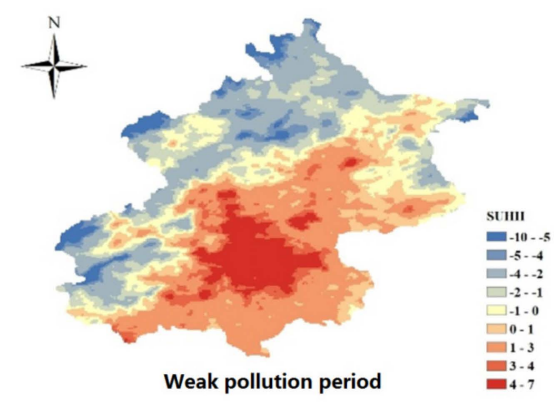

(a)

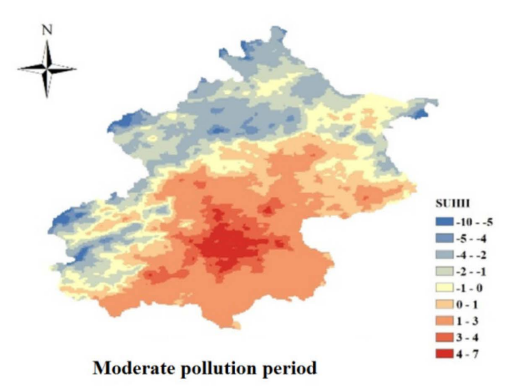

(b)

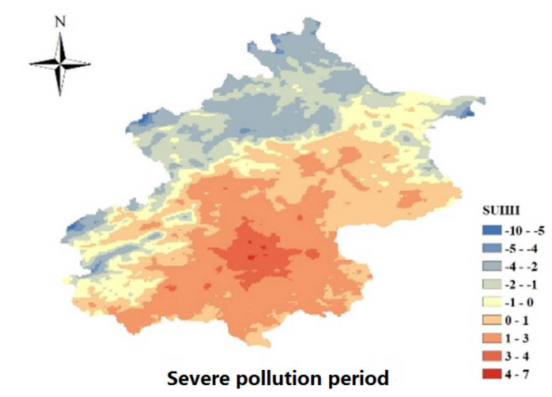

(c)

Figure 3. The spatial distribution of SUHII (surface urban heat island intensity) under different PM2.5

levels. (a) SUHII under light level; (b) SUHII under moderate level; (c) SUHII under serious level.

\subsection{The Correlation between the UHI and PM2.5 Concentration}

The daily mean CUHII and PM2.5 concentration are scatter-plotted in Figure 4a, while the 47 mean SUHII and corresponding PM2.5 concentration are scatter-plotted in Figure 4b. It is expected that the panels illustrate the correlation between UHII and PM2.5 visually.

The Pearson correlation coefficient between CUHII and PM2.5 was $-0.51999(p<0.001)$, while that between SUHII and PM2.5 was smaller $(-0.6115$ with $p<0.001)$. This indicates PM2.5 concentration had significant negative impacts on both CUHII and SUHII, and the impact on SUHII was stronger. It is suggested that PM2.5 could block the energy emission from urban land surfaces seriously, while it had much less influence on canopy temperature change. Thus, high PM2.5 concentration may result in lower SUHII. It is noticed that the number of SUHII value was much less than that of PM2.5, which might render biases in evaluating their correlation.

As both daytime SUHII and nighttime SUHII were available, the impacts of PM2.5 on them were also investigated and shown in Figure 5. The daytime SUHII and PM2.5 concentration are scatter-plotted in Figure 5a, while the nighttime SUHII and corresponding PM2.5 concentration are scatter-plotted in Figure 5b. The Pearson correlation coefficient between CUHII and PM2.5 was -0.6164 with $p<0.001$, which indicates there was a significant negative correlation between PM2.5 and daytime SUHII. High PM2.5 concentration might weaken the daytime SUHII to some extent. On the other hand, the Pearson correlation coefficient between nighttime SUHII and PM2.5 concentration was just -0.2155 with $p=0.1458$, which means there was no significant correlation between them. 


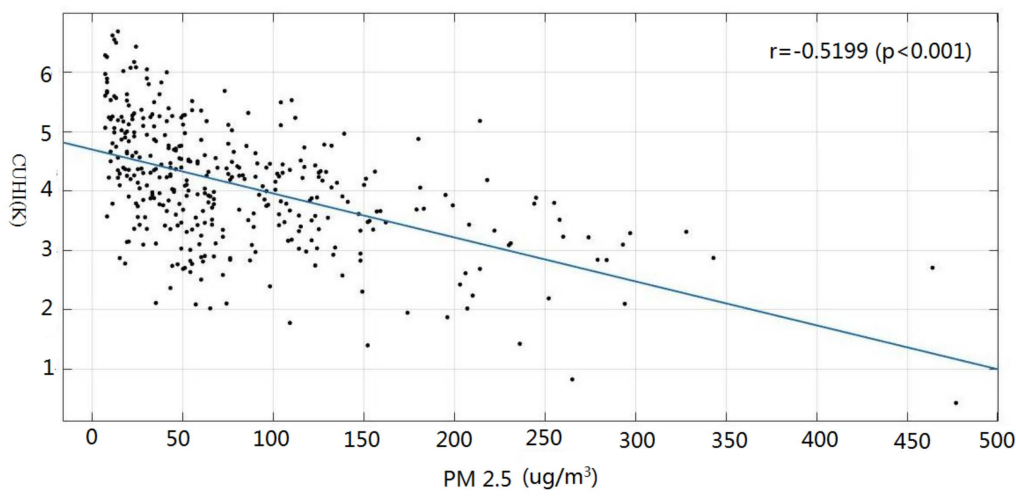

(a)

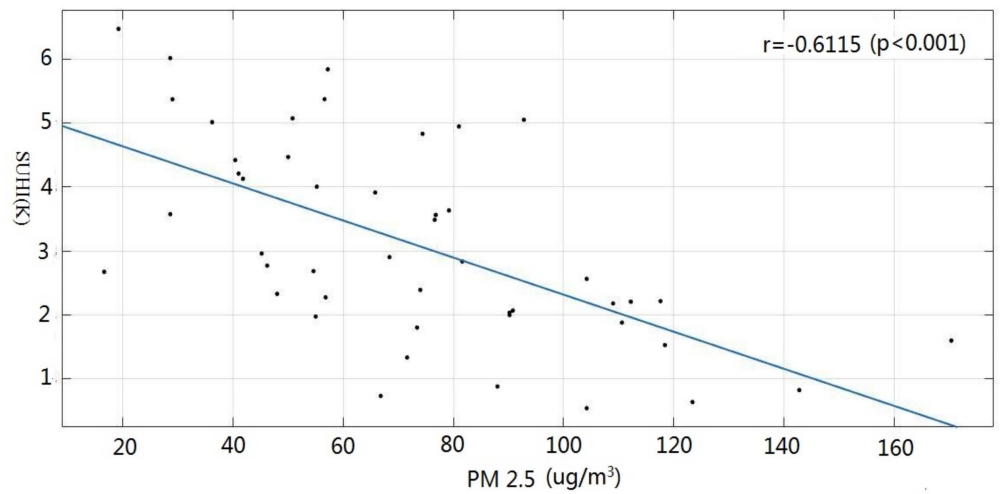

(b)

Figure 4. The scatterplots between UHI (urban heat island) and PM2.5 concentration. (a) CUHII (canopy urban heat island) intensity and PM2.5; (b) SUHII and PM2.5.

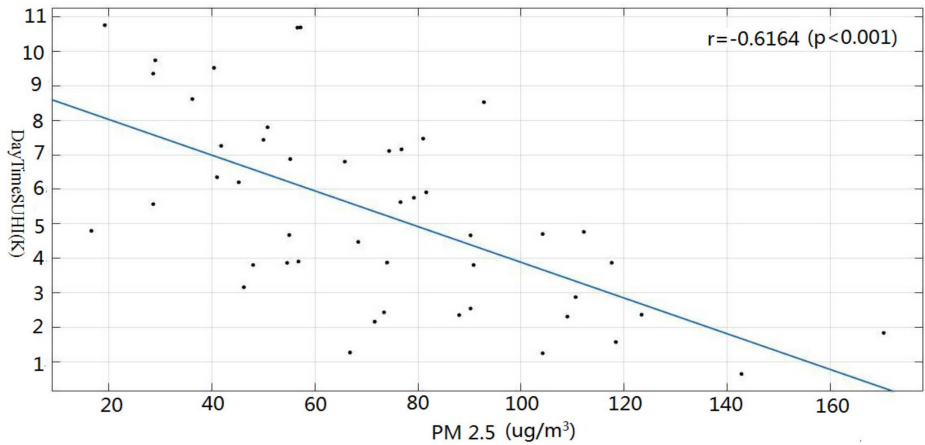

(a)

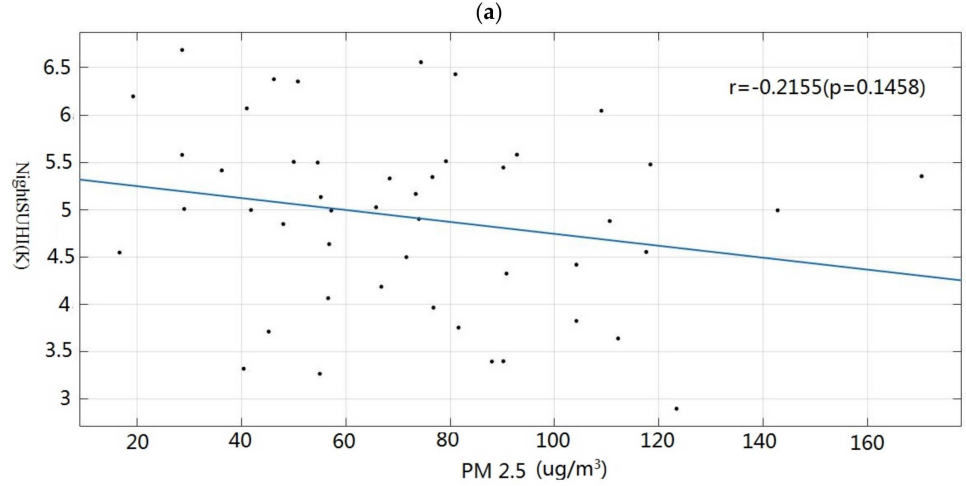

(b)

Figure 5. The scatterplots between PM2.5 and SUHII. (a) The scatterplots between daytime SUHII and PM2.5; (b) the scatterplots between nighttime SUHII and PM2.5. 


\section{Discussions}

UHI has become a serious environmental threat to hundreds of developing cities in China, as it has significant impacts on both daytime and nighttime temperatures, air conditioning loads, water quality, imperious surface lifetimes, ozone and particles [31-33]. Land cover, evapo-transpiration, waste heat from automobiles, industry, civil cooking and heating have significant contributions to UHI [34]. For instance, Reference [35] pointed out that the expansion of impervious surfaces had significant impacts on UHI intensity. Many studies have suggested that modifying the surface and material properties and emissivity of man-made impervious surfaces and increasing the green space can reduce the UHI to some extent [34]. However, the mechanisms of the influence of those natural and anthropogenic causes are very complex, and it is hard to evaluate the UHI and corresponding driving mechanisms with uniform standards. For instance, Reference [7] found that UHI in Shanghai was strongest in Autumn and weakest in Summer, while SUHII became larger in Summer and Autumn in this study, which may be due to the different latitude, climate condition and terrain. In some studies, cities have an intensified nighttime UHI, as the heat releasing from solar energy stored in buildings increased the number and the intensity of heat waves in built-up areas at night [36,37].

Many studies have found high levels of particle concentrations in urban areas have large impacts on the UHI, as increasing particles can change the biogeochemistry and radiative properties of the atmosphere [26-28]. However, it is hard to evaluate the haze contribution to the UHI quantitatively, because of the difficulty in disentangling the opposing effects aerosols have on the surface shortwave and longwave radiation [32]. Generally particles can create a cooling effect on the urban surface, as they can reduce the amount of shortwave radiation reaching the ground surface, because irradiance includes much UV, visible, and near-IR at daytime, and then are more affected by fine particles [28,29]. However, particles also have the potential to increase the longwave radiation energy received at the urban land surface, as they are much more effective in absorbing and emitting radiation in the longwave atmospheric window over both vegetated and urban regions [30]. A particle blanket will affect longwave emissions nearly equally at day and at night. With regard to the fine particles (PM2.5), it interacts much with daytime radiation, and less with the nighttime longwave radiative exchange [27-30]. Our study revealed that PM2.5 concentration has significant negative impacts on daytime UHI, and no significant impact on nighttime UHI, based on a specific experiment with detailed in situ data and satellite images.

The results of this work help deepen our understanding of the dynamics and driving mechanisms of urban thermal environment. For instance, it disclosed the large SUHII was happening in Summer and Autumn in this city, and fine particles had significant impacts on the UHI at daytime. This can help local authorities realize the time when serious UHI happens, and the driving mechanisms that fine particles can also influence UHI, besides terrain, surface properties, civil and industrial heating, etc. Then, more rational and effective polices will be developed.

\section{Conclusions}

As an international metropolis, Beijing has undergone continuous rapid urbanization in the past decades, and both the UHI and PM2.5 concentration are becoming serious environmental problems to this city. With detailed in situ data and satellite images, a specific study on the impacts of fine particles on the city's thermal environment was carried out. In the study, the variation of the metropolis' thermal environment and air quality in 2015 were mapped; and the impacts of fine particles on the city's canopy and surface thermal environment at daytime and night were investigated. The results revealed that CUHII are almost unchanged throughout the year, while SUHII varies greatly in both temporal axis and spatial distribution. The most serious air pollution happened in December, due to the civil heating and stable air. PM2.5 concentration has significant negative impacts on mean SUHII $(r=-0.6115)$ and daytime SUHII $(r=-0.6164)$, less significant negative impact on CUHII $(r=-0.51999)$, and insignificant effect on nighttime SUHII. This work provides an experimental contribution to evaluate the driving mechanisms of UHI and the influence of particles on the urban environment. 
Author Contributions: Writing-original draft preparation, C.Z., C.C., and Y.L.; writing—review and editing, C.Z., and P.G.; supervision and project administration, H.L.

Funding: This research was funded by the China Geological Survey Project [ DD20190511], the Open Fund of Key Laboratory of Urban Land Resources Monitoring and Simulationand the, Ministry of Land and Resources [KF-2018-03-055] and the Natural Science Foundation of China under Grant [41772352].

Acknowledgments: We would like to appreciate the anonymous reviewers, whose comments are all valuable and very helpful for revising and improving our manuscript.

Conflicts of Interest: The authors declare no conflicts of interest.

\section{References}

1. United Nations. World Urbanization Prospects: The 2014 Revision; Department of Economic and Social Affairs, Population Division: New York, NY, USA, 2015.

2. Wang, K.; Wang, J.; Wang, P.; Sparrow, M.; Yang, J.; Chen, H. Influences of urbanization on surface characteristics as derived from the Moderate-Resolution Imaging Spectroradiometer: A case study for the Beijing metropolitan area. J. Geophys. Res. Atmos. 2007, 112. [CrossRef]

3. Shao, Z.; Liu, C. The Integrated Use of DMSP-OLS Nighttime Light and MODIS Data for Monitoring Large-Scale Impervious Surface Dynamics: A Case Study in the Yangtze River Delta. Remote Sens. 2014, 6, 9359-9378. [CrossRef]

4. Fu, H.; Shao, Z.; Fu, P.; Cheng, Q. The Dynamic Analysis between Urban Nighttime Economy and Urbanization Using the DMSP/OLS Nighttime Light Data in China from 1992 to 2012. Remote Sens. 2017, 9 , 416. [CrossRef]

5. Zhang, H.; Ning, X.; Shao, Z.; Wang, H. Spatiotemporal Pattern Analysis of China's Cities Based on High-Resolution Imagery from 2000 to 2015. ISPRS Int. J. Geo-Inf. 2019, 8, 241. [CrossRef]

6. Zhang, L.; Weng, Q.; Shao, Z. An evaluation of monthly impervious surface dynamics by fusing Landsat and MODIS time series in the Pearl River Delta, China, from 2000 to 2015. Remote Sens. Environ. 2017, 201, 99-114. [CrossRef]

7. Zhang, K.; Wang, R.; Shen, C.; Da, L. Temporal and spatial characteristics of the urban heat island during rapid urbanization in Shanghai, China. Environ. Monit. Assess. 2010, 169, 101-112. [CrossRef]

8. Yang, X.; Hou, Y.; Chen, B. Observed surface warming induced by urbanization in east China. J. Geophys. Res. Atmos. 2011, 116. [CrossRef]

9. Van Hove, L.; Jacobs, C.; Heusinkveld, B.G.; Elbers, J.A.; Van Driel, B.L.; Holtslag, A.A.M. Temporal and spatial variability of urban heat island and thermal comfort within the Rotterdam agglomeration. Build. Environ. 2015, 83, 91-103. [CrossRef]

10. Pantavou, K.; Theoharatos, G.; Mavrakis, A.; Santamouris, M. Evaluating thermal comfort conditions and health responses during an extremely hot summer in Athens. Build. Environ. 2011, 46, 339-344. [CrossRef]

11. Huang, L.; Zhao, D.; Wang, J.; Zhu, J.; Li, J. Scale impacts of land cover and vegetation corridors on urbanthermal behavior in Nanjing, China. Theor. Appl. Climatol. 2008, 94, 241-257. [CrossRef]

12. Wu, H.; Wang, T.; Fang, H.; Ma, Y.P.; Han, Y.Q.; Huang, S.; Yao, Y.A.; Shi, J.Q. Impacts of aerosol on the urban heat island intensity in Nanjing. Tran. Atmos. Sci. 2014, 37, 425-431.

13. Cao, J.; Shao, Z.; Guo, J.; Wang, B.; Dong, Y.; Wang, P. A multi-scale method for urban tree canopy clustering recognition using high-resolution image. Optik 2015, 126, 1269-1276. [CrossRef]

14. Zhang, Z.; Tao, J.; Xie, S.; Zhou, L.; Song, D.; Zhang, P.; Cao, J.; Luo, L. Seasonal variations an source apportionment of PM2.5 at urban area of Chengdu. Acta Sci. Circumstantiae 2013, 33, 2947-2952.

15. Pui, D.; Chen, S.; Zuo, Z. PM2.5 in China: Measurements, sources, visibility and health effects, and mitigation. Particuology 2014, 13, 1-26. [CrossRef]

16. Cao, G.; Zhang, X.; Gong, S.; An, X.; Wang, Y. Emission inventories of primary particles and pollutant gases for China. Chin. Sci. Bull. 2011, 56, 781-788. [CrossRef]

17. Li, L.; Wang, W.; Feng, J.; Zhang, D.; Li, H.; Gu, Z.; Wang, B.; Sheng, G.; Fu, J. Composition, source, mass closure of PM2.5 aerosols for four forests in eastern China. J. Environ. Sci. 2010, 22, 405-412. [CrossRef]

18. Ding, A.; Fu, C.; Yang, X.; Sun, J.; Zheng, L.; Xie, Y.; Herrmann, E.; Nie, W.; Petäjä, T.; Kerminen, V.M.; et al. Ozone and fine particle in the western Yangtze River Delta: An overview of 1 yr data at the SORPES station. Atmos. Chem. Phys. 2013, 13, 5813-5830. [CrossRef] 
19. Zhang, L.; Shao, Z.; Diao, C. Synergistic retrieval model of forest biomass using the integration of optical and microwave remote sensing. J. Appl. Remote Sens. 2015, 9, 96069. [CrossRef]

20. Pope, C.A.; Dockery, D.W. Health effects of fine particulate air pollution: Lines that connect. J. Air Waste Manag. Assoc. 2006, 56, 709-742. [CrossRef]

21. Pope, C.A.; Burnett, R.T.; Krewski, D.; Jerrett, M.; Shi, Y.; Calle, E.E.; Thun, M.J. Cardiovascular mortality and exposure to airborne fine particulate matter and cigarette smoke: Shape of the mortality exposure-response relationship. Circulation 2009, 120, 941-948. [CrossRef]

22. Wu, S.; Deng, F.; Wang, X.; Wei, H.; Shima, M.; Huang, J.; Lv, H.; Hao, Y.; Zheng, C.; Qin, Y.; et al. Association of lung function in a panel of young healthy adults with various chemical components of ambient fine particulate air pollution in Beijing, China. Atmos. Environ. 2013, 77, 873-884. [CrossRef]

23. Shao, Z.; Zhang, L.; Wang, L. Stacked Sparse Autoencoder Modeling Using the Synergy of Airborne LiDAR and Satellite Optical and SAR Data to Map Forest Above-Ground Biomass. IEEE J. Sel. Top. Appl. Earth Obs. Remote Sens. 2017, 10, 5569-5582. [CrossRef]

24. Vogel, B.; Vogel, H.; Bäumer, D.; Bangert, M.; Lundgren, K.; Rinke, R.; Stanelle, T. The comprehensive model system COSMO-ART-Radiative impact of aerosol on the state of the atmosphere on the regional scale. Atmos. Chem. Phys. 2009, 9, 8661-8680. [CrossRef]

25. Im, U.; Markakis, K.; Koçak, M.; Gerasopoulos, E.; Daskalakis, N.; Mihalopoulos, N.; Poupkou, A.; Kındap, T.; Unal, A.; Kanakidou, M. Summertime aerosol chemical composition in the Eastern Mediterranean and its sensitivity to temperature. Atmos. Environ. 2012, 50, 164-173. [CrossRef]

26. Solomon, S.; Daniel, J.S.; Neely, R.R.; Vernier, J.P.; Dutton, E.G.; Thomason, L.W. The persistently variable "background" stratospheric aerosol layer and global climate change. Science 2011, 333, 866-870. [CrossRef]

27. Booth, B.; Dunstone, N.J.; Halloran, P.R.; Andrews, T.; Bellouin, N. Erratum: Aerosols implicated as a prime driver of twentieth-century North Atlantic climate variability. Nature 2012, 484, 228-232. [CrossRef]

28. Schmidt, G.A.; Shindell, D.T.; Tsigaridis, K. Reconciling warming trends. Nat. Geosci. 2014, 7, 158-160. [CrossRef]

29. Wu, H.; Wang, T.; Riemer, N.; Chen, P.; Li, M.; Li, S. Urban heat island impacted by fine particles in Nanjing, China. Sci. Rep. 2017, 7, 11422. [CrossRef]

30. Cao, C.; Lee, X.; Liu, S.; Schultz, N.; Xiao, W.; Zhang, M.; Zhao, L. Urban heat islands in China enhanced by haze pollution. Nat. Commun. 2016, 7, 12509. [CrossRef]

31. Zhao, L.; Lee, X.; Smith, R.B.; Oleson, K. Strong contributions of local background climate to urban heat islands. Nature 2014, 511, 216-219. [CrossRef]

32. Lin, C.-Y.; Chen, F.; Huang, J.C.; Chen, W.C.; Liou, Y.A.; Chen, W.N.; Liu, S.C. Urban heat island effect and its impact on boundary layer development and land-sea Circulation over northern Taiwan. Atmos. Environ. 2008, 42, 5635-5649. [CrossRef]

33. Parker, D.E. Urban heat island effects on estimates of observed climate change. Wiley Interdiscip. Rev. Clim. Chang. 2010, 1, 123-133. [CrossRef]

34. Phelan, P.; Kaloush, K.; Miner, M.; Golden, J.; Phelan, B.; Silva III, H.; Taylor, R.A. Urban Heat Island: Mechanisms, Implications, and Possible Remedies. Annu. Rev. Environ. Resour. 2015, 40, 285-307. [CrossRef]

35. Shao, Z.; Fu, H.; Li, D.; Altan, O.; Cheng, T. Remote sensing monitoring of multi-scale watersheds impermeability for urban hydrological evaluation. Remote Sens. Environ. 2019, 232, 111338. [CrossRef]

36. Mohsin, T.; Gough, W.A. Trend analysis of long-term temperature time series in the Greater Toronto Area (GTA). Theor. App. Climatol. 2010, 101, 311-327. [CrossRef]

37. Shao, Z.; Fu, H.; Fu, P.; Yin, L. Mapping Urban Impervious Surface by Fusing Optical and SAR Data at the Decision Level. Remote Sens. 2016, 8, 945. [CrossRef]

(C) 2019 by the authors. Licensee MDPI, Basel, Switzerland. This article is an open access article distributed under the terms and conditions of the Creative Commons Attribution (CC BY) license (http://creativecommons.org/licenses/by/4.0/). 